\title{
Radiological Decontamination, Survey, and Statistical Release Method for Vehicles
}

Michael E. Goodwill

Jeffrey W. Lively

Robert L. Morris

June 1996

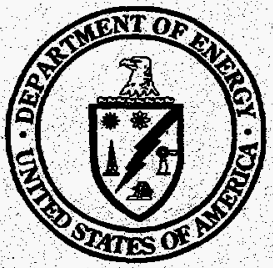

U.S. Department of Energy Grand Junction Projects Office

Approved for public release; distribution is unlimited. 


\section{DISCLAIMER}

Portions of this document may be illegible in electronic image products. Images are produced from the best available original document. 
DOE/ID/12584-271

GJPO-MRAP-27

\title{
Radiological Decontamination, Survey, and Statistical Release Method for Vehicles
}

\author{
Michael E. Goodwill \\ Jeffrey W. Lively \\ Robert L. Morris
}

June 1996

Prepared for

U.S. Department of Energy Albuquerque Operations Office Grand Junction Projects Office

Prepared by

Rust Geotech

Grand Junction, Colorado

Work Performed Under DOE Contract No. DE-AC04-86ID12584 
This report was prepared as an account of work sponsored by an agency of the United States Government. Neither the United States Government nor any agency thereof, nor any of their employees, makes any warranty, express or implied, or assumes any legal liability or responsibility for the accuracy, completeness, or usefulness of any information, apparatus, product, or process disclosed in this report, or represents that its use would not infringe privately owned rights. Reference herein to any specific commercial product, process, or service by trade name, trademark, manufacturer, or otherwise, does not necessarily constitute or imply its endorsement, recommendation, or favoring by the United States Government or any agency thereof. The views and opinions of authors expressed herein do not necessarily state or reflect those of the United States Government or any agency thereof. 


\section{Contents}

Page

Abstract $\ldots \ldots \ldots \ldots \ldots \ldots \ldots \ldots \ldots \ldots \ldots \ldots \ldots \ldots \ldots \ldots \ldots$

Introduction $\ldots \ldots \ldots \ldots \ldots \ldots \ldots \ldots \ldots \ldots \ldots \ldots \ldots \ldots \ldots \ldots \ldots \ldots$

Survey Terminology $\ldots \ldots \ldots \ldots \ldots \ldots \ldots \ldots \ldots \ldots \ldots \ldots \ldots \ldots$

Development of a Statistical Sampling Plan $\ldots \ldots \ldots \ldots \ldots \ldots \ldots \ldots \ldots$

Define Inspection Attributes and Acceptance Criteria $\ldots \ldots \ldots \ldots \ldots \ldots \ldots$

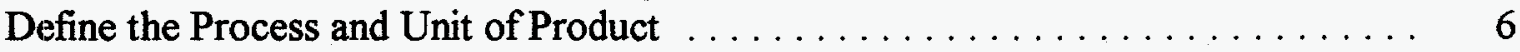

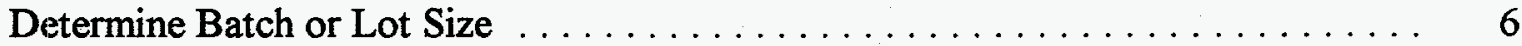

Establish the Acceptable Quality Level . . . . . . . . . . . . . . . 8

Select the Inspection Level . . . . . . . . . . . . . . . . . . . $\ldots$

Identify Minor, Major, or Critical Defects $\ldots \ldots \ldots \ldots \ldots \ldots \ldots$

Use Tables in Military Standards $\ldots \ldots \ldots \ldots \ldots \ldots \ldots \ldots \ldots$

Process Requirements $\ldots \ldots \ldots \ldots \ldots \ldots \ldots \ldots \ldots \ldots \ldots \ldots \ldots \ldots \ldots$

Example Statistical Sampling Plan $\ldots \ldots \ldots \ldots \ldots \ldots \ldots \ldots \ldots \ldots \ldots \ldots \ldots$

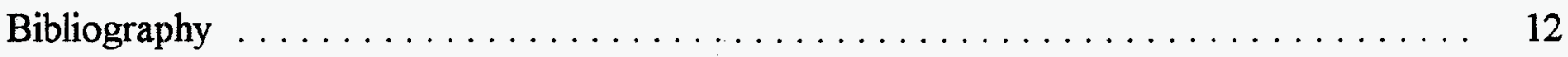

Attachment 1. Statistical Survey Method for Release of Vehicles $\ldots \ldots \ldots \ldots \ldots \ldots$

\section{Table}

Table 1. Contamination Values Presented in Table 2-2 of the DOE Radiological 


\begin{abstract}
Earth-moving vehicles (e.g., dump trucks, belly dumps) commonly haul radiologically contaminated materials from a site being remediated to a disposal site. Traditionally, each vehicle must be surveyed before being released. The logistical difficulties of implementing the traditional approach on a large scale demand that an alternative be devised. A statistical method* for assessing product quality from a continuous process was adapted to the vehicle decontamination process. This method produced a sampling scheme that automatically compensates and accommodates fluctuating batch sizes and changing conditions without the need to modify or rectify the sampling scheme in the field. Vehicles are randomly selected (sampled) upon completion of the decontamination process to be surveyed for residual radioactive surface contamination. The frequency of sampling is based on the expected number of vehicles passing through the decontamination process in a given period and the confidence level desired. This process has been successfully used for 1 year at the former uranium millsite in Monticello, Utah (a cleanup site regulated under the Comprehensive Environmental Response, Compensation, and Liability Act). The method forces improvement in the quality of the decontamination process and results in a lower likelihood that vehicles exceeding the surface contamination standards are offered for survey. Implementation of this statistical sampling method on Monticello projects has resulted in more efficient processing of vehicles through decontamination and radiological release, saved hundreds of hours of processing time, provided a high level of confidence that release limits are met, and improved the radiological cleanliness of vehicles leaving the controlled site.
\end{abstract}

"Military Standard (MIL-STD) 105E, "Sampling Procedures and Tables for Inspection by Attributes." 


\section{Introduction}

Contamination levels on any given vehicle leaving a radioactive site must be below the specified removable and total contamination levels (henceforth referred to as Table 2-2 values) in Table 2-2 of the U.S. Department of Energy (DOE) Radiological Control Manual (see Table 1). The method prescribed by the DOE Radiological Control Manual to meet these requirements is a representative survey, including all accessible surfaces that may have become contaminated, of every vehicle leaving the area. These requirements also specify that surfaces inaccessible for surveying be evaluated to assess the potential for contamination. Because vehicles have a significant surface area with many surfaces inaccessible for measurement, the strict (or default) application of the requirements for release of these vehicles from contamination areas results in a laborious, largely ineffective process. In Article 371 of the Radiological Control Manual, DOE recognizes the special nature of construction and environmental restoration activities and allows its contractors to establish technically equivalent alternative controls to meet certain requirements in the manual, provided the contractor justifies and documents the alternative controls. One area where DOE authorizes alternative controls is in "methods to obtain representative samples for release of equipment and materials from the work areas." A statistical survey method qualifies as an alternative control.

Use of a statistical survey method is appropriate to reduce costs and delays caused by excessive radiological surveys on the site when each of the following conditions exists:

- The radiological nature of the contaminants involved is well characterized.

- The vehicles are subjected to a consistent and well-defined decontamination process.

- Significant contamination has not been detected to date on vehicles leaving the decontamination pad.

A statistical survey method will meet the desired confidence level to ensure that contamination levels in excess of the limits are not being released, provided the above conditions are true. In addition, the potential is low for a person to receive a committed effective dose equivalent (CEDE) in excess of 10 millirem (mrem) from loss of contamination control when dealing with low levels of radioactivity.

Survey frequency and methodology should not be relied upon as contamination-control measures in themselves, but rather as a quality-control measurements to verify the effectiveness of the decontamination procedure. This methodology appropriately places the emphasis on the contamination-control methods and decontamination technique rather than on the survey, which is essentially a sample to determine an attribute associated with the vehicle-surface contamination. 
Table 1. Contamination Values Presented in Table 2-2 of the DOE Radiological Control Manuala

\begin{tabular}{|c|c|c|}
\hline $\begin{array}{l}\text { Nuclide } \\
\text { (See Note 1) }\end{array}$ & $\begin{array}{l}\text { Removable } \\
\text { (dpm/100 } \mathrm{cm}^{2} \text { ) } \\
\text { (See Note 2) }\end{array}$ & $\begin{array}{c}\text { Total (fixed + } \\
\text { removable) } \\
\left(\text { dpm/100 } \mathrm{cm}^{2}\right) \\
\text { (See Note 3) }\end{array}$ \\
\hline $\begin{array}{l}\text { U-natural, U-235, U-238, and } \\
\text { associated decay products }\end{array}$ & 1,000 alpha & 5,000 alpha \\
\hline $\begin{array}{l}\text { Transuranics, Ra-226, Ra-228, } \\
\text { Th-230, Th-228, Pa-231, } \\
\text { Ac-227, and l-129 }\end{array}$ & 20 & 500 \\
\hline $\begin{array}{l}\text { Th-nat, Th-232, Sr-90, Ra-223, } \\
\text { Ra-224, U-232, I-125, I-126, I-131, } \\
\text { and I-133 }\end{array}$ & 200 & 1,000 \\
\hline $\begin{array}{l}\text { Beta-gamma emitters (nuclides with } \\
\text { decay modes other than alpha } \\
\text { emission or spontaneous fission) } \\
\text { except Sr-90 and others noted } \\
\text { above. Includes mixed fission } \\
\text { products containing Sr-90. }\end{array}$ & 1,000 beta-gamma & 5,000 beta-gamma \\
\hline $\begin{array}{l}\text { Tritium organic compounds, } \\
\text { surfaces contaminated by HT, HTO, } \\
\text { and metal tritide aerosols }\end{array}$ & 10,000 & 10,000 \\
\hline
\end{tabular}

$\mathrm{dpm}=$ disintegrations per minute and $\mathrm{cm}^{2}=$ centimeters squared.

Notes:

1. The values in this table apply to radioactive contamination deposited on, but not incorporated into, the interior of the contaminated item. Where contamination by both alpha- and beta-gamma-emitting nuclides exists, the limits established for the alpha- and beta-gammaemitting nuclides apply independently.

2. The amount of removable radioactive material per $100 \mathrm{~cm}^{2}$ of surface area should be determined by swiping the area with dry fitter or soft absorbent paper while applying moderate pressure and then assessing the amount of radioactive material on the swipe with an appropriate instrument of known efficiency. For objects with a surface area less than $100 \mathrm{~cm}^{2}$, the entire surface should be swiped, and the activity per unit area should be based on the actual surface area. Except for transuranics, Ra-228, Ac-227, Th-228, Th-230, $\mathrm{Pa}-231$, and alpha emitters, it is not necessary to use swiping techniques to measure removable contamination levels if direct scan surveys indicate that the total residual contamination levels are below the values for removable contamination.

3. The levels may be averaged over 1 square meter provided the maximum activity in any area of $100 \mathrm{~cm}^{2}$ is less than three times the values in Table $2-2$.

This methodology may not be appropriate for the unconditional release of vehicles at the end of the project or for off-site (non-DOE-controlled) work, maintenance, or repair. For release from transportation controls or for off-site work, maintenance, or repair, consideration should be given to performing complete inspections and surveys, including case-by-case evaluations of the likelihood that inaccessible surfaces are contaminated.

The statistical elements of this plan are adapted from Department of Defense Military Standard (MIL-STD) 105E, "Sampling Procedures and Tables for Inspection by Attributes," and MIL-STD-1235C, "Single and Multilevel Continuous Sampling Procedures and Tables for Inspection by Attributes." Although the details of a sampling plan may differ to fit a given scenario, the basic process is consistent, and the statistics are valid. 


\section{Survey Terminology}

The following terminology from MIL-STD-105E and MIL-STD-1235C is presented to demonstrate its application to this survey method:

Acceptable Quality Level-The maximum number of defects per hundred units that may be considered satisfactory as a process average (i.e., the confidence level). An acceptable quality level (AQL) of 5 percent corresponds to a confidence level of 95 percent.

Attribute-The parameter that is to be compared to some value deemed to be acceptable (standard). For this sampling plan, two attributes are evaluated: (1) residual visible materials on any external surface and (2) surface radioactive contamination. Each attribute must have a defined acceptance or rejection criterion.

Batch-A collection of units of product from which a sample will be drawn and inspected to determine conformance with the acceptability criteria. A batch will consist of units of product of the same type, grade, class, and size that have undergone the same process.

Continuous Process - A continuous operation for which minimum and maximum acceptance criteria have been established. A continuous process can be inspected to determine conformance with the acceptability criteria. If any part of the process does not meet the minimum acceptability criteria, the process is halted to correct the deficient element.

Defect-The failure of a unit of product to meet the acceptance criterion for a given attribute when sampled.

Inspection Level-A criteria that specifies how many units of product must be inspected and how many defective units of product can be discovered before the entire lot or batch must be rejected. MIL-STD-105E identifies three general inspection levels: levels I, II, and III. Level 1 requires inspection of fewer units of product; however, the number of defective units of product that can be discovered before the entire lot or batch must be rejected is lower as well. Level III is used when greater discrimination is required. Level $I$ is the inspection level that is most commonly used.

Lot-A number of units of product undergoing the same process that will be inspected on a statistical basis. The lot unit used in this survey method is a single work shift. This is the most commonly defined lot unit for any commercial continuous process system.

Normal Sampling - The batch sampling plan that will be used as long as the process apparently is producing products of the selected AQL or better.

Sample-Each inspection and survey performed on a unit of product selected at random without regard to its quality. 
Tightened Sampling - The batch sampling plan to be used (or switched to) if evidence indicates that quality has deteriorated. If tightened sampling has been initiated because of an apparent deterioration in process quality, it should remain in effect until a specified number of consecutive batches (usually five) have been accepted during the original inspection.

Unit of Product-Each item that has been subjected to a consistent process. 


\section{Development of a Statistical Sampling Plan}

The steps in the development of a statistical sampling plan are

1. Determine the attributes that should be inspected.

2. Define the values (criteria) by which each attribute will be judged to determine its acceptance or rejection.

3. Define the process and the unit of product.

4. Determine the lot (or batch) size (including the type of process to be used-batch or continuous process).

5. Establish the AQL.

6. Select the inspection level.

7. Decide if the failure of each individual attribute inspected represents a minor, major, or critical defect.

8. Use the tables in associated military standards (MIL-STD-105E for batch processes and MIL-STD-1235C for continuous processes) to determine the sample code letters, minimum sample size, and number of allowable defects.

\section{Define Inspection Attributes and Acceptance Criteria}

The first step in developing a statistically valid sampling plan is to define the inspection attribute(s), and the second step is to define the acceptance criteria for each of these attributes. For a vehicle used in radiologically contaminated areas, surface contamination is the attribute that must be evaluated to release the vehicle from control. The acceptance criteria for this attribute are presented in Table 1 in this document and in Figure IV-1 of DOE Order 5400.5, Radiation Protection of the Public and the Environment.

For remediation work involving soils, an additional criterion-no visible residual material-also may be applied. This additional criterion is useful for several reasons.

- The soils contaminating the vehicle surfaces typically are low specific activity materials. To concentrate enough activity to meet the surface contamination limits prescribed, a reasonably large, visible, amount of material must be present.

- Experience in remediating uranium mill product materials indicates that it is unlikely that surface contamination limits might be exceeded without being able to see the material. 
- The bulk of the materials associated with uranium mill product remediation are of a particle size that is large enough to be visible in the concentration necessary to approach the surface contamination limits.

- The decontamination process is likely to use this same criterion as its end point. By analyzing for this criterion, an immediate visual assessment of the effectiveness of the decontamination process can be made.

For the purposes of this application, any vehicle with visible residual material or contamination levels exceeding Table 1 values will be considered a defect.

\section{Define the Process and Unit of Product}

The second step is to define the process and the unit of product. For soil remediation involving the use of vehicles to move materials out of and into the contaminated area, a thorough, welldefined decontamination process (independent of the sampling process) must be established. Decontamination of a vehicle is the consistent process that allows the use of a statistical sampling approach. The unit of product is the vehicle that undergoes the decontamination process.

\section{Determine Batch or Lot Size}

Third, the batch or process lot size is determined. Any process can be viewed as a batch when the criteria that define a batch are applied. However, sampling plans presented in MIL-STD-105E assume that the units of product are being collected together (as if in a holding pen), awaiting random selection for inspection. These sampling plans are based on the following premise: if an unacceptable number of units of product fail to meet the acceptance criteria, (1) additional samples can be obtained (tightened sampling), (2) the entire batch could be rejected, or (3) a 100-percent inspection can be required of each unit of product without risk of releasing an unacceptable number of defective units.

When the process does not afford the luxury of retaining units of product until the entire batch is certified to be acceptable, the result is a continuous process. Confidence is required in the effectiveness of the continuous process to produce units of product that will meet the designed acceptance criteria. This confidence factor is the essential difference between batch or lot-by-lot sample plans outlined in MIL-STD-105E and those outlined for the continuous process in MIL-STD-1235C. The proper application of these criteria not only help define the batch size but are vitally important to the validity of the statistics that will be used to access the decontamination process.

A lot, or batch, should consist of units of product of the same type, grade, class, and size that have undergone the same process. In the case of vehicles, consideration should be given to the similarities and differences between different classes or types of vehicles. For example, vehicles with tracks may be classed separately from vehicles with rubber tires because of the difference in potential for vehicle tracks to become contaminated by traversing the same area and the relative effectiveness of the decontamination process for this type of vehicle as compared to typical 
vehicles with rubber tires. Essentially, if the decontamination process must be modified or the inspection altered to adequately decontaminate and assess the acceptability of a vehicle for release from radiological controls, then that vehicle is not part of the same batch or lot.

Once the characteristics that define each unit of product are assessed and the batch is defined, the batch size can be estimated. The batch (lot) size is the number of units of product (vehicles of a given class) going through the decontamination process in one run or work shift. For this survey method, the batch size is limited to one work shift to account for the potentially changing radiological conditions on a low-level radioactive remediation site and for a broad-scale change in the personnel conducting the decontamination. Therefore, the collection of all standard vehicles (e.g., vehicles with rubber tires) leaving the decontamination pad on a single day is considered a batch.

The basic statistics for both the batch and continuous processes are the same. The same minimum fraction of the estimated batch size must be sampled for either process. The difference is the degree of confidence presumed for each process. A process that is untried or unproven or has little operational history should not be readily trusted to produce a consistent product—one that meets the standard.

To obtain this confidence, the methodology of a continuous sampling plan requires increased sampling frequency up front, with a relaxation to the minimum sampling frequency necessary after no defects are found in the previous inspections. This increased initial inspection frequency may be approached in many different ways. Some model plans call for 100-percent sampling for $i$ number of samples, followed by a reduction to the minimum specified frequency.

Because the 100-percent sampling proposed by some of the more simplistic continuous sampling plans may produce an undue economic stress or production constraint, a multilevel continuous sampling scheme may be useful, especially when the effectiveness of the process is already well established. Multilevel sampling plans call for the initial inspection of all units of product produced. But as each unit inspected meets the defined criteria, the sampling frequency gradually is reduced to the minimum acceptable sample frequency. This multilevel sampling scheme still puts the emphasis on the process quality with each new lot but gives some relief to the production schedule, provided the quality remains high.

NOTE: The organization responsible for the project's production-the owner of the vehicles trying to egress the radiologically controlled area-should employ the decontamination technicians. This way, any slowdown in production caused by process failure cannot be assessed to the organization responsible for the inspection and certification of the process.

If, at any time during the inspection, a unit of product fails to meet an inspection criterion, the unit is rejected as a failure, and the process, rather than the batch, is called into question. The consequences of this failure and the questions it raises about the process quality mandate that the inspection frequency return to the initial 100-percent scheme. Continued failure of a unit of 
product to meet the acceptance criteria is cause to suspend the use of the statistical sampling plan altogether until the cause(s) for failure can be determined and corrected.

\section{Establish the Acceptable Quality Level}

Establishing the AQL is the fourth step in the development of the statistical sampling plan. The $\mathrm{AQL}$ is the central point of the statistical sampling scheme. Because the AQL represents, in essence, the confidence level expected of the sampling plan to identify units of product with defects, it should be carefully chosen. Factors that should be considered are

- Regulatory constraints.

- Scientific consequences of failure to identify a unit of product as defective.

- Perceived consequences (e.g., public concern, corporate, and DOE image in the community) of failure to identify a unit as defective.

- Economics involved with the sampling plan.

- Production constraints.

- Ability to recover a defective product that already has left the process if the process is found to be ineffective at producing the desired quality level.

- Effectiveness of available detection methods used to measure an attribute against the acceptance standard.

- Accepted industry standards.

In the case of radioactive materials or equipment contaminated with low-level radioactive materials presumed to be present in the environmental remediation arena, public perception is a major concern. However, current ability to detect surface contamination at the prescribed DOE limit with instruments in the field is probably about 50-percent reliable. As a compromise, an AQL of 5 percent was chosen, which corresponds to a 95-percent confidence level. This AQL matches the generally accepted industry standard and closely approximates the confidence level expected in a survey of every vehicle involved in the process.

\section{Select the Inspection Level}

The fifth step is to select the inspection level to be used, which determines the relationship between the lot (or batch) size and the sample size. Three general inspection levels are defined in MIL-STD-105E: levels I, II, and III. Typically, inspection level II is used.

Level I may be used when less discrimination is needed; this level requires inspection of fewer units of product, however the number of defects before an entire lot or batch must be rejected is 
lower as well. The sampling risks are greatest for inspection level I. Level III is used when greater discrimination is desired; this level requires inspection of a greater number of units of product; however, use of this level can be an economic disadvantage. Inspection level II was chosen for this survey method.

\section{Identify Minor, Major, or Critical Defects}

A sampling methodology may define defects found in an inspection as minor, major, or critical. However, because of the potential health and safety risks, environmental considerations, and public perception, any failure of the inspection criteria in this sampling method is considered a critical defect.

\section{Use Tables in Military Standards}

Once the inspection level has been chosen and the lot or batch size has been determined, the last step is to establish the minimum sample size by using tables presented in the military standards. These tables also specify the minimum number of allowable rejects before the lot or batch must be rejected, according to the AQL established. 


\section{Process Requirements}

The application of a statistical sampling plan relies upon a consistent process. To ensure process consistency, certain controls must be imposed on the process. A prescribed and approved vehicle decontamination process should consist of the following elements:

- The decontamination equipment and system have been tested and proven effective at the specific location.

- The decontamination equipment and system are capable of delivering a decontamination wash agent at the designed flow rate and pressure.

- The decontamination process precludes the recontamination of other vehicles or previously decontaminated parts of the same vehicle.

- Decontamination technicians receive training on the process and its importance.

- The criteria for completion of the decontamination process are defined clearly.

On the basis of application of definitions presented previously, the following guidance meets or exceeds the criteria of MIL-STD-105E for an acceptable, statistical, single sampling methodology (at inspection level III), including requirements for implementation of normal and tightened sampling. Reduced sampling will not be used. 


\section{Example Statistical Sampling Plan}

The statistical sampling plan that follows provides an example of a method for radiological decontamination, survey, and release of vehicles. Attachment 1 contains Procedure HS -330.02 , "Statistical Survey Method for Release of Vehicles," from the HS\&S Desktop Procedures Manual (Manual 303), Volume 2, which implements this sampling plan.

As long as no vehicle inspected and surveyed is rejected (i.e., a defect), inspect and survey only the $1 \mathrm{st}, 2 \mathrm{nd}, 4 \mathrm{th}, 6 \mathrm{th}, 10 \mathrm{th}$, and 15 th vehicle, and every 7 th vehicle randomly selected thereafter leaving the decontamination pad each day.

If any inspected and surveyed vehicle is found to have visible residual materials or to be contaminated at levels greater than Table 1 values, repeat the decontamination process and inspect and survey the unit of product until no visible residual materials are present and contamination levels are below Table 1 values. Then restart the inspection and survey count pattern again (i.e., inspect and survey vehicles $1,2,4,6,10,15,22$, etc., beginning with the next vehicle in line for decontamination). If any two surveyed vehicles on any given shift are found to have visible residual materials or to be contaminated at levels greater than Table 1 values, then abandon this statistical survey method until the reason for persistent contamination is identified and corrected.

In addition, if more than 1 hour has elapsed since the last vehicle left the decontamination pad, then the next vehicle should be surveyed, regardless of its position in the count pattern. In this case, the count pattern need not be restarted. The reason for this provision is to compensate automatically for a worst-case scenario of an unusually small batch size on a given shift. While the estimated batch size in this case is 75 vehicles, on any given day only 8 vehicles may need to be decontaminated.

The minimum batch size for which this sampling plan will consistently provide the desired confidence level is 51 . However, because the design of the counting pattern is weighted to increase the inspection and survey frequency automatically for small batches, the risk of failing to meet the desired confidence level is minimal, even if the batch size on a given day is smaller than 51. This decrease in batch size is considered to be an acceptable risk; however, the responsible project health physicist should periodically review the applicable data to verify the continued adequacy and statistical validity of the sampling plan. If radiological conditions change so that the number of vehicles requiring decontamination and release changes substantially, the statistical sampling plan should be reevaluated. 


\section{Bibliography}

Duncan, Acheson J., 1974. Quality Control and Industrial Statistics, Fourth Edition, Richard D. Irwin, Inc., Homewood, Illinois.

Rust Geotech, n.d. HS\&S Desktop Procedures Manual (Manual 303), Volume 2, Procedure HS-304, "Contamination Surveys and Equipment and Material Release," U.S. Department of Energy, Grand Junction Projects Office, Grand Junction, Colorado.

, n.d. HS\&S Desktop Procedures Manual (Manual 303), Volume 2, Procedure HS-330.02, "Statistical Survey Method for Release of Vehicles," U.S. Department of Energy, Grand Junction Projects Office, Grand Junction, Colorado.

, n.d. Management Policies Manual (Manual 100), U.S. Department of Energy, Grand Junction Projects Office, Grand Junction, Colorado.

U.S. Department of Defense, 1995. "Sampling Procedures and Tables for Inspection by Attributes," MIL-STD-105E, Index of Specifications and Standards, February 27, 1995.

, 1988. "Single and Multilevel Continuous Sampling Procedures and Tables for Inspection by Attributes," MIL-STD-1235C, Index of Specifications and Standards, March 15, 1988.

U.S. Department of Energy, 1993. DOE Order 5400.5, Radiation Protection of the Public and the Environment, January 7, 1993.

, 1992. Radiological Control Manual, DOE/EH-0256T, June 1992.

U.S. Department of Transportation, 1992. Exemption for Hauling Low-Level Radioactive Materials, DOT-E 10594, May 28, 1992. 


\title{
Attachment 1
}

\section{Statistical Survey Method for Release of Vehicles}

\author{
Procedure HS-330.02 in the Rust Geotech \\ HS\&S Desktop Procedures Manual (Manual 303)
}




\title{
RUST GEOTECH INC.
}

\author{
HEALTH AND SAFETY \\ DESKTOP PROCEDURE
}

MANUAL 303

\section{STATISTICAL SURVEY METHOD for RELEASE of VEHICLES}

HS-330.02

REVISION 0

EFFECTIVE DATE $-5-1-96$

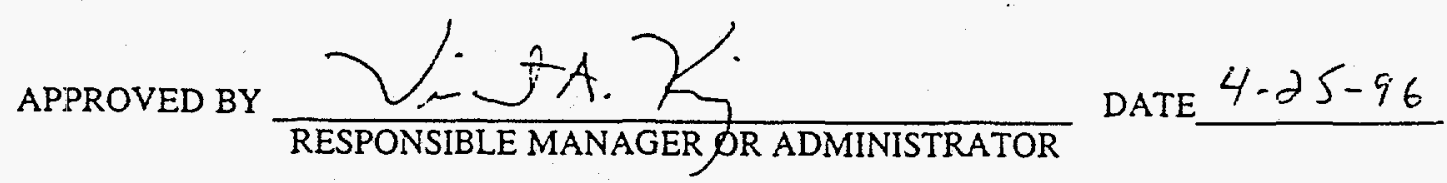


TABLE OF CONTENTS

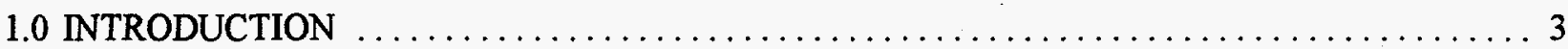

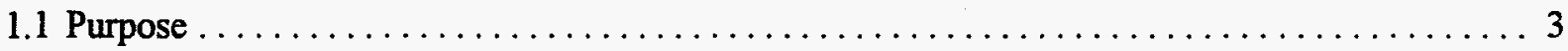

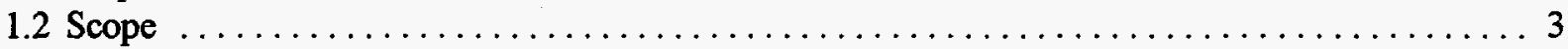

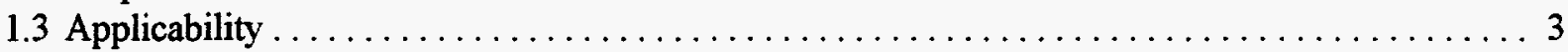

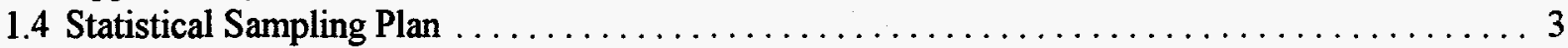

2.0 PRECAUTIONS, LIMITATIONS AND NOTES $\ldots \ldots \ldots \ldots \ldots \ldots \ldots \ldots \ldots \ldots \ldots \ldots \ldots$

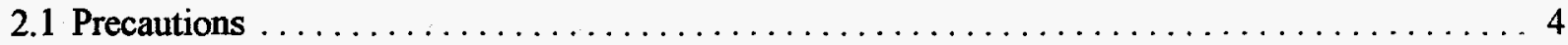

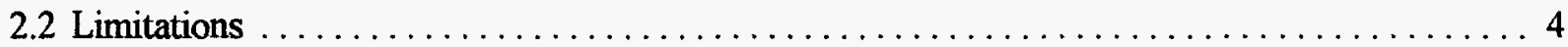

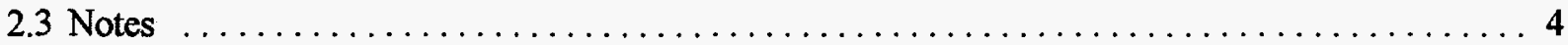

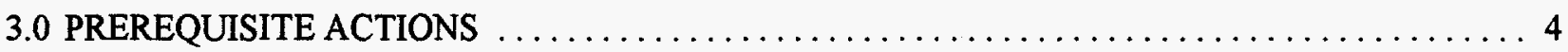

4.0 SELECTION of VEHICLES for SURVEY \& INSPECTION $\ldots \ldots \ldots \ldots \ldots \ldots \ldots \ldots \ldots$

5.0 INSPECTION of SELECTED VEHICLES FOLLOWING DECONTAMINATION $\ldots \ldots \ldots \ldots \ldots 5$

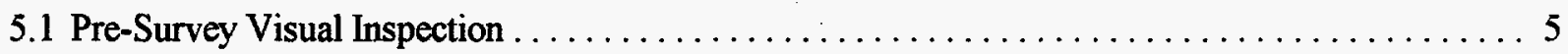

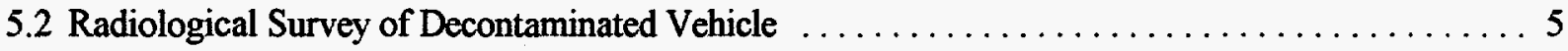

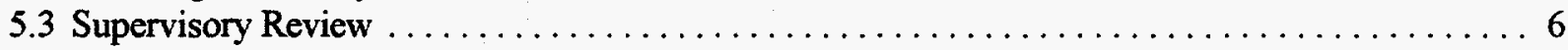

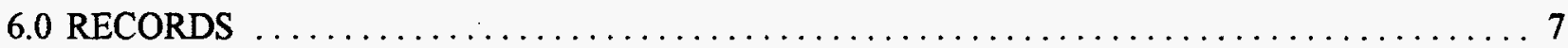

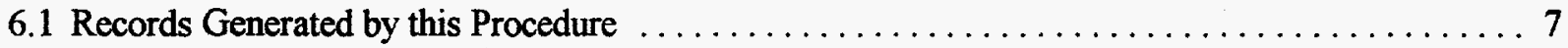

6.2 Record Disposition . . . . . . . . . . . . . . . . . . . . 7

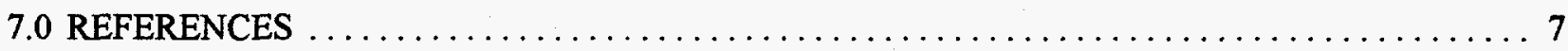

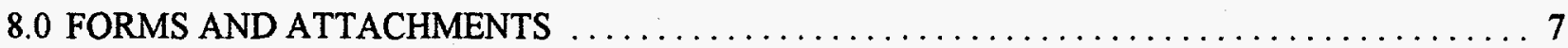

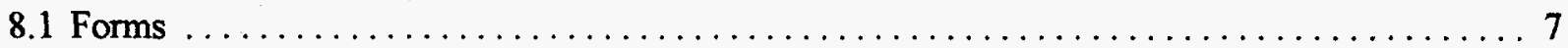

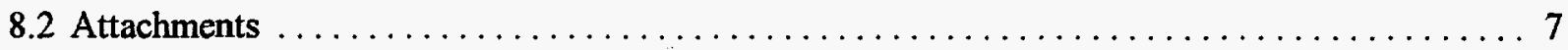




\begin{tabular}{|l|c|c|c|}
\hline RUST Geotech Inc. & HS-330.02 & Revision No. 0 & Page 3 of 7 \\
\hline \multicolumn{3}{|c|}{ Statistical Survey Method for Release of Vehicles } \\
\hline
\end{tabular}

\subsection{INTRODUCTION}

\subsection{Purpose}

This site-specific procedure provides guidance for the application of statistical survey methodology, including survey frequency and required survey elements, for the release of wheeled vehicles from areas at Monticello Projects posted as Contamination Areas.

\subsection{Scope}

This procedure establishes a mechanism for ensuring compliance the Radiological Control Manual requirements for the release of vehicles contaminated with uranium mill tailings. The use of this procedure assumes that the vehicles have already been subjected to the decontamination procedure described in Health \& Safety Desktop Manual 303, Vol. 2, Procedure HS-330.01. Radiological surface contamination surveys prescribed by this procedure are performed in accordance with Health and Safety Desktop Manual 303, Vol. 2, Procedure HS-304, "Contamination Surveys and Equipment \& Material Release."

\subsection{Applicability}

This procedure is applicable only to wheeled vehicles contaminated with uranium mill tailings and which have been subjected to a consistent decontamination process as described in procedure HS-330.01. It is not applicable to the unrestricted release of the bulk containers on the vehicles which are used to contain DOT regulated radioactive material in transport. It is not applicable for vehicles or equipment other than wheeled vehicles.

\subsection{Statistical Sampling Plan}

The sampling frequencies including methods for random selection used in this procedure are defined in the sampling plan and approved by the project health physicist.

At the beginning of the day (or new shift) establish the following sequence (count pattern) for each vehicle subject to the decontamination process. Following decontamination, survey the first, second, fourth, sixth, tenth, fifteenth, and one vehicle (randomly selected) out of every group of seven thereafter.

If any vehicle selected for inspection and survey is rejected, then the vehicle will be returned for further decontamination. Any vehicle that has been rejected will automatically be reinspected and surveyed, and will not count as a vehicle in the count pattern following any subsequent decontamination efforts.

If a vehicle selected for inspection and survey is rejected, then restart the survey count pattern again, beginning with the next vehicle in line for decontamination.

If weather conditions change (e.g., it begins to snow, rain, or soil conditions change), then restart the survey count pattern again.

If more than 1 hour has elapsed since the last vehicle to leave the decontamination pad, then the next vehicle should be surveyed, regardless of its position in the count pattern. 


\begin{tabular}{|l|r|r|r|}
\hline RUST Geotech Inc. & HS-330.02 & Revision No. 0 & Page 4 of 7 \\
\hline \multicolumn{3}{|c|}{} \\
Statistical Survey Method for Release of Vehicles \\
\hline
\end{tabular}

If any two (2) surveyed vehicles are found to be contaminated on any given shift, then abandon this statistical sampling method and survey all vehicles until the reason for persistent contamination is identified and abated.

The technician in charge of the decontamination pad operations has the authority to randomly select a vehicle for inspection and survey, regardless of its position in the count pattern.

NOTE: $\quad$ Such a selection does not substitute or replace selection of subsequent vehicles required to be selected and surveyed randomly in accordance with this procedure.

\subsection{PRECAUTIONS, LIMITATIONS AND NOTES}

\subsection{Precautions}

A. Great care should be exercised to prevent inadvertent movement of the vehicle being inspected and surveyed. Parking brakes should be set and wheels blocked to prevent inadvertent movement of vehicles during the inspection.

\subsection{Limitations}

A. Use of the statistical sampling plan described in this procedure is predicated on the number of vehicles subjected to decontamination and surveillance each shift (day). Nominally, the frequency called out in the sampling plan is designed to achieve a $95 \%$ confidence in the ability to identify an inadequate decontamination process when at least 51 vehicles are decontaminated and offered for survey each shift.

\subsection{Notes}

A. If the daily batch size is smaller than the design minimum batch size of 51 vehicles for more than 2 shifts in any calendar week, use of the statistical sampling process should be suspended until batch sizes increase to a number consistently above the minimum or until a new sampling frequency can be established.

\subsection{PREREQUISITE ACTIONS}

[1] Verify that the subject vehicle has first gone through an approved, prescriptive decontamination process in accordance with Health \& Safety Desktop Manual 303, Vol. 2, Procedure HS-330.01.

[2] Verify that the vehicle to be inspected has the parking brake set and that at least one wheel is securely blocked before proceeding with this procedure. 


\begin{tabular}{|l|c|c|c|}
\hline RUST Geotech Inc. & HS-330.02 & Revision No. 0 & Page 5 of 7 \\
\hline \multicolumn{3}{|c|}{ Statistical Survey Method for Release of Vehicles } \\
\hline
\end{tabular}

\subsection{SELECTION of VEHICLES for SURVEY \& INSPECTION}

\section{Approved Count Pattern}

Following decontamination, survey the first, second, fourth, sixth, tenth, fifteenth, and one vehicle (randomly selected) out of every group of seven thereafter.

[1] Begin (or restart) the survey \& inspection count pattern when any of the following conditions occur:

1. The beginning of a new shift.

2. When changes in the site conditions increase the likelihood of vehicles becoming contaminated

3. When any vehicle fails the inspection criteria specified in section 5.0.

[2] Record the vehicle ID\# in the "Item Surveyed" column on the "Radiological Survey Map," form GJPO 1553, for each vehicle that passes through the decontamination process.

[3] Record the vehicle's position in the count pattern in the "Remarks" column on the "Radiological Survey Map," form GJPO 1553

\subsection{INSPECTION of SELECTED VEHICLES FOLLOWING DECONTAMINATION}

\subsection{Pre-Survey Visual Inspection}

[1] Visually inspect the selected vehicle for visible residual material.

[2] IF the vehicle has visible residual materials, THIEN,
[a] Reject the vehicle decontamination
[b] Record the rejection in the "Release" column on the "Radiological Survey Map," noting any special or anomalous conditions in the remarks section of form GJPO 1553
[c] Immediately notify the technician in charge of the decontamination pad operations
[d] Return the vehicle to the decontamination pad for further decontamination.

[3] IF the vehicle's position in the count pattern indicates that a radiological survey is required, OR more than 1 hour has elapsed since the last vehicle was released, THIEN perform the survey in accordance with section 5.2 below. 


\subsection{Radiological Survey of Decontaminated Vehicle}

[1] Perform a contamination survey of the exterior accessible surfaces of the vehicle including trailers, as applicable, in accordance with H\&S Desktop Procedure HS-304 to include but not limited to:

1. Tires, Wheel wells, Underside of fenders, \& Mud flaps

2. Dump gate area and Openings

3. Running boards \& Steps

4. Hitch (on vehicles with trailers)

5. Undercarriage (representative)

[2] IF the vehicle does not meet the release criteria specified in H\&S Desktop procedure HS-304, THEN,

[a] Reject the vehicle decontamination,

[b] Record the rejection in the "Release" column on the "Radiological Survey Map," noting any special or anomalous conditions in the remarks section of form GJPO 1553,

[c] Immediately notify the technician in charge of the decontamination pad operations,

[d] Return the vehicle to the decontamination pad for further decontamination,

[e] Resurvey the rejected vehicle in accordance with step [1] above, and

[f] Start the vehicle sampling count pattern over again.

[3] IF the vehicle meets the release criteria specified in H\&S Desktop procedure HS-304, THEN

[a] Release the vehicle from the site,

[b] Record the vehicle's release in the "Release" column on the "Radiological Survey Map," (GJPO 1553) referencing the approved release criteria as justification and authorization, and

[c] Notify the technician in charge of the decontamination pad operations of the satisfactory survey \& inspection.

[4] Forward the completed Radiological Survey Map(s) (GJPO 1553) to the Project Lead Radiological Control Technician for supervisory review and signature.

\subsection{Supervisory Review}

[1] Review the completed survey documentation in accordance with H\&S Desktop Procedure Manual, Volume 1, Procedure HSSESH-0003, "Documentation," to ensure conformance with the record quality criteria specified by the Health \& Safety Manual, Volume 1, Procedure 1.4, "Records Management Plan."

[2] Compare the survey results with similar data to determine if trends are developing or unexpected results were obtained.

[a] Notify the Project Safety Officer and the Project Health Physicist of any trends or unexpected results. 
[3] Verify that an adequate number of vehicles were offered this shift to continue use of the statistical sampling procedure.

\subsection{RECORDS}

\subsection{Records Generated by this Procedure}
A. GJPO 1553, "Radiological Survey Map"

\subsection{Record Disposition}

[1] Maintain the documentation generated by this procedure as "Q" level records in accordance with the Management Policies Manual (Manual 100), Section 13, Records Management, and the Health and Safety Manual (Manual 103), Procedure 1.4, Records Management Plan.

\subsection{REFERENCES}

A. MIL-STD-105E, "Sampling Procedures and Tables for Inspection by Attributes."

B. RUST Geotech Health \& Safety Manual 103, Volume 2, "Site Specific Radiological Control Manual"

C. RIJST Geotech Desktop Procedures Manual 303, Volume 2, HS-304, "Contamination Surveys and Equipment \& Material Release"

D. RUST Geotech Desktop Procedures Manual 303, Volume 2, HS-330.01, "Decontamination Procedure for Wheeled Vehicles"

E. RUST Geotech Management Policies Manual 100

F. DOT-E 10594, Department of Transportation Exemption for Hauling Low Level Radioactive Materials

G. Technical Basis Document No. MONT-94-01 "Vehicle Decontamination, Survey, and Statistical Release Method for the Monticello Project Mill Site"

\subsection{FORMS AND ATTACHMENTS}

\subsection{Forms}

None.

\subsection{Attachments}

None. 